\title{
Facing up to fraud
}

September 25, 2002 was a sad day for science. It was a sad day in particular for Jan Hendrik Schön and his employer, Bell Labs, but all of us are saddened by the findings of the Beasley inquiry into allegations of scientific misconduct by Schön and his co-authors.

Schön's gravity-defying career had him apparently heading for Stockholm, following his prodigious output of some 100 papers, many reporting groundbreaking results, within 5 years of his $\mathrm{PhD}$. But the inability of rivals to reproduce many of the results, and growing concerns earlier this year about the published data led to 25 papers being scrutinized this summer for data misrepresentation.

The committee led by Malcolm Beasley has done a tremendous job and should be applauded for the professional way it has handled this inquiry. But those of us who held out a glimmer of hope that fraud was not the only explanation, have been crushed by the news that for 16 out of the 24 investigated allegations, Schön (but not his co-authors) is guilty of scientific misconduct.

Fraud occurs in every walk of life, so why are we so surprised and shocked when scientists are involved? Is it, perhaps, because the scientific enterprise relies so much on trust that it is hard for us to imagine serious misconduct. Or is there a complacency associated with the notion that false results will always be found out in the end? Either way, we are often ill-prepared to deal with the consequences.

The Commentary by Paul Grant on page 139 of this issue addresses some of the questions left unanswered by the Beasley report; how much responsibility co-authors should assume, for example. Grant argues, in particular, that misconduct is more easily detected in industrial laboratories than their academic equivalents, which raises the uncomfortable notion that undetected fraud is perhaps much more common than we like to think.

There is no indication that Schön thought that what he was doing was normal practice: he appears to have gone to great lengths to hide his actions from his colleagues. But good laboratory practice is more often assumed than enforced. It would be wrong to consider this inquiry a watershed for scientific conduct, and to treat every groundbreaking result with suspicion. But it would also be wrong to remain complacent, and to chalk these unhappy events up to the actions of one rogue researcher. Had he been caught sooner the collateral damage - to other careers and reputations — would have been far less.

Whistle blowing is a thankless task in any industry, but when your peers are members of funding review boards, the incentive to be courageous and speak up about suspected wrongful activity is even lower. We should applaud those who did. To encourage whistle blowers, and to prevent needlessly damaging the reputations of the accused or the accuser, institutional policies towards allegations of fraud must be transparent. As scientific publishers we have a similar responsibility towards our authors and reviewers, and the editors of Nature Materials will always take allegations of misconduct that arise during peer review very seriously. In such cases, we will require a written and

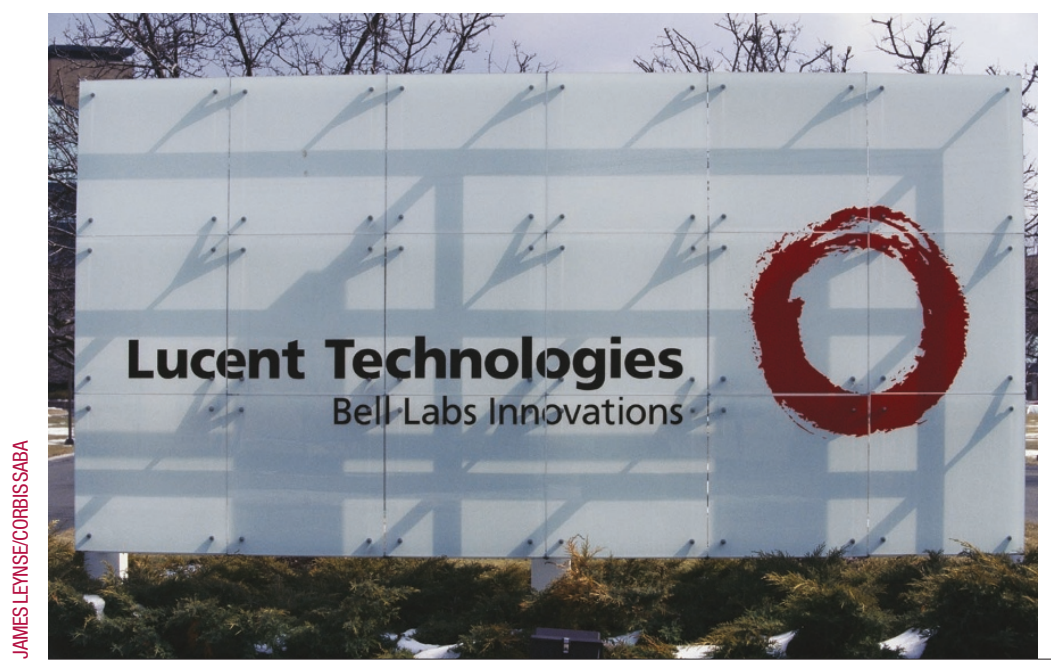
signed rationale for the allegations before presenting them to the authors, and external institutions if necessary.

Emotional responses to this sorry episode are likely to be intense but short-lived. There was anger by some at the wasted resources - in terms of both time and funds - that were diverted to the new lines of enquiry that Schön's fraudulent discoveries, first in superconductivity and then in molecular electronics stimulated. But we should remember that science progresses through trial and error, most often error. Even when scientists get things wrong, science itself may ultimately gain if people ask questions or develop ideas that otherwise would not have been explored. As the economist Vilfredo Pareto once said "Give me a fruitful error any time, full of seeds, bursting with its own corrections. You can keep your sterile truth for yourself." Only time will tell if Schön's deception was a fruitful one for science. 